\title{
Ukraine struggles with rise in PTSD
}

$\mathrm{O}$ $\mathrm{n}$ the Maidan in Kiyv, the site of protests that ended in bloodshed in February 2014, almost every ledge and concrete step is covered with hasty memorials to the fallen. Fresh flowers and red glass candles surround framed pictures of dead soldiers. Next to them, rows of placards depicting photos from the war zone, from tanks on the move to soldiers playing soccer in shelled gymnasiums. In between the placards and pedestrians, volunteers from various organizations walk back and forth with little pails hanging from their necks, asking for donations to help wounded soldiers and their families.

These volunteers know, as does everyone in Ukraine, that there are legions of traumatized soldiers returning from the east. Since the war with Russia started in April 2014, some 70000 Ukrainian soldiers have fought and approximately 2500 have died. Soldiers have seen friends killed in front of them with high-powered Russian artillery. Some have lost limbs; others have seen entire towns turned to rubble.

The physical injuries are evident, but the mental health issues often remain hidden due to a strong stigma. Many returning soldiers simply do not know how to cope with what they have witnessed, according to Prof. Oleh Chaban, a psychiatrist with decades of experience across the former Soviet Union, who bluntly outlined some of the challenges facing Ukraine in coping with the traumas of war.

"We do not have national diagnostic protocols, treatment and rehabilitation systems for patients with acute reactions to stress and [posttraumatic stress disorder] PTSD," he said from his office in Kyiv.

He also notes that the broad knowledge base that western mental health professionals might take for granted does not exist in Ukraine. "We do not have consistent systems of training to work with patients with PTSD. We do not have enough specialists, nor enough quality knowledge and literature on PTSD." Despite this, he stressed, the willingness of professionals and volunteers to help is strong. One of those lending a hand is Elena Zaiakina, who

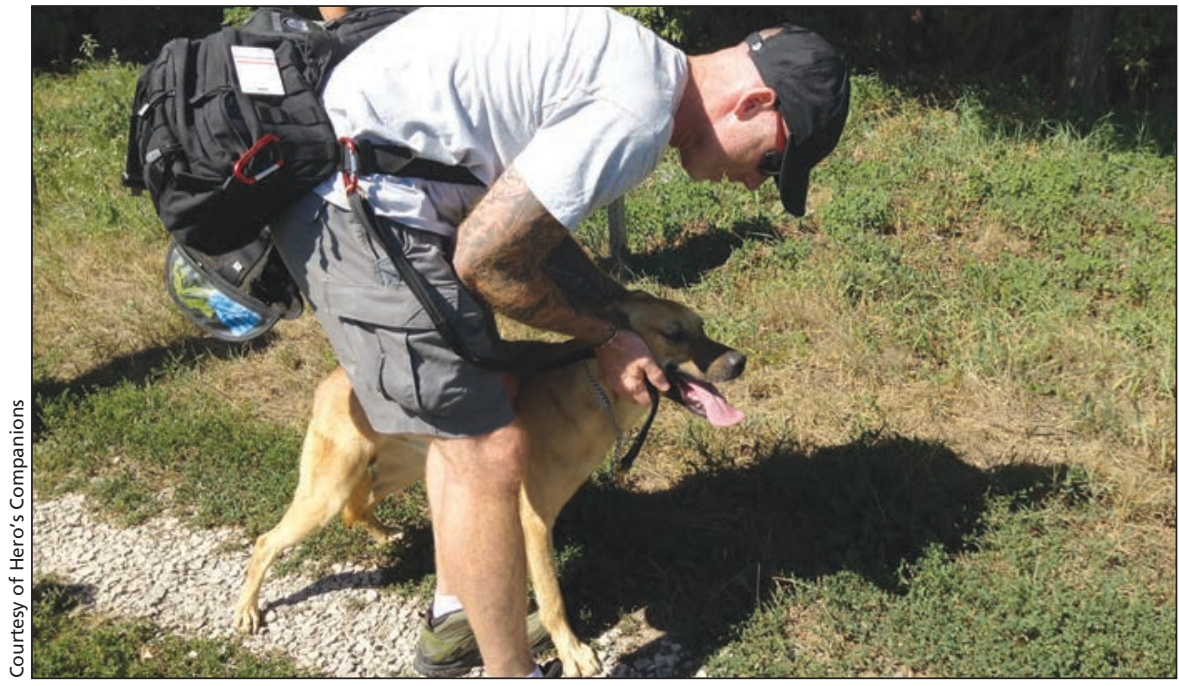

Marc Lapointe, a Canadian Forces veteran working with Hero's Companion in Ukraine, assesses a candidate therapy dog near Kyiv.

has overseen rehabilitation programs in Ukraine since 1996, including programs to treat alcoholism and help women fleeing domestic violence.

"I think right now," she noted in an email from Ukraine, "the most urgent issue is readaptation and resocialization of soldiers returning from the war." Soldiers return home and often do not know how to deal with what they have experienced. According to Zaiakina, this often leads to alcoholism, a problem that plagues the Ukrainian army.

Facing a protracted economic crisis, the Ukrainian government can provide only piecemeal services to returning soldiers. This also means that Zaiakina's centre does not have regular funding, and she struggles to keep up with the sheer level of need. Soldiers and family members have to pay some or all of the costs of programs and, she stresses, this is becoming more and more of a problem for them.

Many Ukrainian-Canadians are leading efforts to help tackle the problem of PTSD in Ukraine. Kalyna Kardash, with the League of Ukrainian Canadian Women, started Hero's Companion in the summer of 2015. Based on the Courageous Companions animal therapy program in Canada, the goal of Hero's Companion is to provide psychological service dogs to veterans and place therapy dogs in hospitals across Ukraine.

When Kardash and her colleagues were in Kyiv in August raising awareness of the program, two carloads of soldiers happened to stop by. "You could just tell two of the guys looked like they had PTSD," she said, "and they were giving us examples like "I was recovering in a hospital bed and fireworks went off and I was just terrified."” Kardash told the soldiers about the program and their response was enthusiastic.

"We asked them 'Do you want to see our dogs? Do you want to go play with them?" said Kardash. Once the soldiers met and played with the therapy dogs, "we couldn't get them to leave," she laughs. "They just stayed and stayed."

Projects like Hero's Companion, Guardian Angels, Hope Worldwide's Helping Hand for Ukraine program and others make a difference, but more help is needed.

Back in his office not far from the Maidan, Chaban lauds the enthusiasm of the scores of volunteers who currently provide most of the help to treat soldiers with PTSD in Ukraine, but is worried that not all of them are trained properly to work with traumatized soldiers. "They might actually be making it worse," he said. "We need funds for professional training, for professional health workers, general practitioners and volunteer workers." - Michael Colborne, Edmonton, Alta.

CMAJ 2015. DOI:10.1503/cmaj.109-5160 